\title{
Novel and ecofriendly UV-Spectrophotometry methods for estimation of Tolvaptan using hydrotropic agent
}

\author{
Mangesh R. Patil ${ }^{1}$, Amod S. Patil ${ }^{2}$, Atul A. Shirkhedkar ${ }^{3 *}$ \\ ${ }^{1}$ M.Pharm Student, ${ }^{2}$ Assistant Professor, ${ }^{3}$ Vice Principal and HOD, Dept. of Pharmaceutical Chemistry, R. C. Patel Institute \\ of Pharmaceutical Education and Research, Shirpur, Dhule, Maharashtra, India
}

*Corresponding Author: Atul A. Shirkhedkar

Email: shirkhedkar@gmail.com

\begin{abstract}
The aim of present investigation is to establish simple and economical UV- Spectrophotometric methods for estimation of Tolvaptan using Zero order UV-Spectrophotometric absorbance method and Zero Order- Area under curve (AUC) method with the application of hydrotropic solubilization phenomenon. Tolvaptan is non-peptide vasopressin V2 receptor antagonist. It is completely insoluble in water. Hydrotropic agent, sodium lauryl Sulfate (SLS) 5\% $w / v$ was used to enhance the solubility of Tolvaptan. Maximum absorption for Tolvaptan was found to be at $269 \mathrm{~nm}$. The methods are based upon measurement of absorbance at $269 \mathrm{~nm}$ and integration of area under curve for analysis of Tolvaptan in the wavelength range of 263.2-282.2 $\mathrm{nm}$. The drug followed linearity in the concentration range of $3-18 \mu \mathrm{g} / \mathrm{mL}$ with correlation coefficient value $\mathrm{r}^{2}>0.99$ for both methods. The proposed methods were validated for accuracy, precision, repeatability and ruggedness, as per ICH guidelines. The proposed methods were applied for qualitative and quantitative estimation of Tolvaptan in pharmaceutical formulation and results were found in good agreement with the label claimed. Developed methods can be used for routine analysis of Tolvaptan in bulk and tablets.
\end{abstract}

Keywords: Sodium Lauryl Sulphate, Tolvaptan, UV- Spectrophotometry - Area under Curve, UV-Spectrophotometry, Hydrotropy.

\section{Introduction}

Tolvaptan is non-peptide vasopressin (VP) V2 receptor antagonist that inhibits water re-absorption in the kidney by competitively blocking VP binding, resulting in water diuresis without significantly changing total electrolyte excretion. ${ }^{1,2}$ Tolvaptan chemically is $\mathrm{N}-\{4-[(5 \mathrm{R})-7$-chloro-5-hydroxy-2,3,4,5tetrahydro-1H-1-benzazepine-1-carbonyl]-3methylphenyl\}-2-methyl benzamide. The chemical structure of Tolvaptan is depicted in Fig. 1.

In Literature, few liquid chromatography procedures have been reported for the analysis of Tolvaptan. ${ }^{3,4}$ Few UV-Spectrophotometric methods have been reported using methanol as solvent. ${ }^{5,6}$

Hydrotropy is defined as the increase in solubility of various substances in water and it could possible by addition of large amounts of hydrotropic agents. ${ }^{7}$ The poorly water-soluble drugs have been solubilized using various hydrotropic solutions. Sodium benzoate, Niacinamide, Sodium salicylate, Sodium acetate, Sodium citrate and Urea have been employed to enhance the aqueous solubility of many poorly watersoluble drugs. ${ }^{8-10}$

The aim of the present investigation is to develop a simple, rapid, precise, reproducible and economical method for the estimation of the Tolvaptan using UVSpectrophotometric by studying absorbance and Area under curve (AUC) techniques.

\section{Chemical and Reagents}

Tolvaptan was gifted by Enaltec Lab Mumbai, Sodium lauryl Sulphate purchased from MOLYCHEM Mumbai and Tablets (Hyponat 15mg) were purchased from local market.

\section{Instrumentation}

1. Spectrophotometer: UV-2450 Shimadzu, Japan

2. Software: UV Probe 2.21

3. Sample cell: $1 \mathrm{~cm}$ quartz cuvette

4. Lamp: Deuterium Lamp Wavelength range 200 400nm

5. Spectral Slit width: $1.0 \mathrm{~nm}$ 
6. Weighing Balance: Shimadzu AUX-120

\section{Experimental}

\section{Preliminary solubility studies and selection of solvent}

Solubility of Tolvaptan was determined in different hydrotropic agent includes Sodium Benzoate, Sodium Acetate, Sodium Citrate, Urea, Benzalkonium chloride, Pluronic (F68,F127), Potassium Acetate, and Polyethylene Glycol. Solubility of Tolvaptan was found improved by sodium lauryl Sulphate solution. The drug is completely soluble in SLS at various concentration $30 \%, 20 \%, 10 \%$, and $5 \% w / v$. For further studies minimum concentration $5 \% w / v$ of SLS is used.

\section{Preparation of stock standard solutions}

Preparation of $5 \% \mathrm{w} / \mathrm{v}$ sodium lauryl sulfate solution: $50 \mathrm{~g}$ of sodium lauryl sulfatewas dissolved in $1000 \mathrm{ml}$ of water.

The stock standard solution: An appropriate weight of $10 \mathrm{mg}$ of Tolvaptan was transferred into 100 $\mathrm{mL}$ of volumetric flaskcontaining $50 \mathrm{ml}$ of sodium lauryl sulfate $(5 \% \mathrm{w} / \mathrm{v})$ solution, sonicated for $15 \mathrm{~min}$ and volume made upto $100 \mathrm{ml}$ with same solvent to obtain concentration of $100 \mu \mathrm{g} / \mathrm{mL}$. The working standards were prepared by dilution of the stock standard solution.

\section{Determination of $\lambda$ max and calibration curve}

A fixed volume of $1.0 \mathrm{~mL}$ of Tolvaptan from stock solution was transferred to $10 \mathrm{~mL}$ volumetric flask, diluted to mark with sodium lauryl sulfate $(5 \% \mathrm{w} / \mathrm{v})$ to obtain concentration of $10 \mu \mathrm{g} / \mathrm{mL}$. The resultant solution was scanned in UV range (400-200 nm) in 1.0 cm cell against solvent blank. The spectrum showed an absorption maximum at $269 \mathrm{~nm}$. In Method I absorbance at $269 \mathrm{~nm}$ was considered for analysis while for Method II two wavelengths 263.2-282.2 nm were selected for determination of Area under Curve [AUC]. Optical Characteristics of Tolvaptan presented in Table 1. Zero order UV-spectrum showing maximum absorbance and AUC are shown in Fig. 2.

An appropriate volume of stock solution in the range of $0.3-1.8 \mathrm{~mL}$ were transferred in series of 10 $\mathrm{mL}$ volumetric flask, volume was made up to $10 \mathrm{~mL}$ with sodium lauryl Sulphate $(5 \% w / v)$ solution to get concentration of $3-18 \mu \mathrm{g} / \mathrm{mL}$ and absorbance was measured at $269 \mathrm{~nm}$ (method I) and Zero order- AUC was recorded in between the wavelength range of 263.2-282.2 nm (Method II) against the blank. Calibration curves were prepared by plotting concentration versus absorbance and AUC Fig. 3.

\section{Analysis of marketed formulation}

Twenty tablets were accurately weighed and average weight determined, an amount of powdered drug equivalent to $10 \mathrm{mg}$ of Tolvaptan was transfer into 100 $\mathrm{mL}$ volumetric flask containing $50 \mathrm{ml}$ of sodium lauryl sulfate $(5 \% \mathrm{w} / \mathrm{v})$ sonicated for $15 \mathrm{~min}$. The volume was made up to the mark with same solvent and filtered through $0.45 \mu \mathrm{m}$ Whatman filter paper. A suitable volume of solution was further diluted with $5 \%$ sodium lauryl sulfate to obtain concentration $9 \mu \mathrm{g} / \mathrm{mL}$ of Tolvaptan for tablet assay. These sample solutions were scanned at selected wavelengths in Method I \& Method II and the results were obtained. From the respected linear regression equations, the concentrations were determined. The procedure was repeated for six times and the results are shown in Table 2.

\section{Validation}

The method was validated according to ICH guidelines for validation of analytical procedures in order to determine the linearity, sensitivity, precision, ruggedness and accuracy for the Tolvaptan in bulk and tablet dosage form.

\section{Accuracy}

To estimate the accuracy of both the proposed methods, recovery studies were executed out at $80 \%$, $100 \%$ and $120 \%$ of the test concentration as per ICH guidelines. To the pre-analyzed sample solution (6 $\mu \mathrm{m} / \mathrm{ml}$ ), a known amount of drug standard was added at $80 \%, 100 \%$ and $120 \%$ and solutions were reanalyzed by proposed methods. The experiments were performed for three times at each level for each method. The results of the recovery studies are reported in Table 3. 


\section{Precision}

Precision of the methods were studied as intra-day, inter-day variations and repeatability. Precision was determined by analyzing the concentration of 6,9 , and $12 \mu \mathrm{g} / \mathrm{mL}$.

To determine the degree of repeatability of the methods, statistical evaluation was carried out. Repeatability was determined by analyzing Tolvaptan concentration of $9 \mu \mathrm{g} / \mathrm{mL}$ for six times and results reported in Table 4.

\section{Ruggedness}

Ruggedness of the proposed method was determined by analysis of aliquots from homogenous slot by two analyst using same operational and environmental conditions and the results are reported in Table 5.

\section{Sensitivity}

The sensitivity of proposed methods was estimated in terms of estimating Detection Limit (DL) and Quantitation Limit (QL) which were calculated using formulae " $\mathrm{DL}=3.3 \times \mathrm{N} / \mathrm{B}$," and "QL $=10 \times \mathrm{N} / \mathrm{B}$ " where " $\mathrm{N}$ " is average standard deviation of the absorbance or peak areas of the Tolvaptan $(n=3)$, taken as a measure of noise, and " $\mathrm{B}$ " is the slope of the corresponding calibration curve.

\section{Results and Discussion}

In the present investigation, hydrotropic solubilization is employed to enhance the aqueous solubility of poorly water-soluble drugs Tolvaptan in bulk and in tablet dosage forms. By selecting proper hydrotropic agents, the use of organic solvents in analysis may be decreased to a greater extent. For the solubility studies, different hydrotropic agent was tried but optimum solubility was achieved in sodium lauryl sulfate (5\% $w / v)$ solution. In Method I \& II, linearity of Tolvaptan "was found to be in the range of $03-18 \mu \mathrm{g} / \mathrm{mL}$, with correlation coefficient ( $\mathrm{r} 2>0.99)$. Marketed brand of tablet dosage form were analyzed. The amounts of Tolvaptan determined by 'Method I' \& Method II was found to be $99.01 \%$ and $99.73 \%$, respectively. In both these methods, precision was studied as repeatability, inter and intra-day variations at three different concentrations of tolvaptan and \% RSD was found to be less than 2. The accuracy of method was determined by calculating mean percentage recovery. It was determined at $80 \%, 100 \%$ and $120 \%$ level and $\%$ recovery was found to be in the range $98.5-99.4$ and 98.7-99.6 for method I and II respectively. The ruggedness of the methods was studied by two different analysts using the same operational and environmental conditions and \% RSD found to be less than 2. DL and QL were found to be 0.269 and 0.815 , respectively for Method I and DL and QL were found to be 0.371 and1.126 respectively for Method II indicating adequate sensitivity of the methods.

Table 1: Optical characteristics of Tolvaptan

\begin{tabular}{|c|c|c|}
\hline Parameter & Method I & Method II \\
\hline Wavelength & $269 \mathrm{~nm}$ & $261.20-278.20 \mathrm{~nm}$ \\
\hline Linearity range $(\mu \mathrm{g} / \mathrm{ml})$ & $03-18$ & $03-18$ \\
\hline Correlation coefficient & 0.9992 & 0.9994 \\
\hline
\end{tabular}

Table 2: Analysis of Tablet

\begin{tabular}{|c|c|c|c|c|c|}
\hline & Label Claim(mg) & Conc. $(\boldsymbol{\mu g} / \mathbf{m l})$ & \%Amount Found & $\mathbf{\pm}$ SD & \% RSD $(\mathbf{n}=\mathbf{6})$ \\
\hline Method I & 15 & 9 & 99.01 & 0.873 & 0.882 \\
\hline Method II & 15 & 9 & 99.73 & 0.668 & 0.670 \\
\hline
\end{tabular}

\section{Validation Parameters}

Table 3: Accuracy (\% Recovery)

\begin{tabular}{|c|c|c|c|c|c|}
\hline & $\begin{array}{c}\text { Initial Amount } \\
(\boldsymbol{\mu g} / \mathbf{m l})\end{array}$ & $\begin{array}{c}\text { Amount Added } \\
(\boldsymbol{\mu} \mathbf{g} / \mathbf{m l})\end{array}$ & $\begin{array}{c}\text { Amount Recovered } \\
(\boldsymbol{\mu g} / \mathbf{m l}, \mathbf{n}=\mathbf{3})\end{array}$ & \% Recovered & \%RSD \\
\hline Method I & 6 & 4.8 & 10.73 & 98.55 & 0.703 \\
\hline
\end{tabular}




\begin{tabular}{|c|c|c|c|c|c|}
\hline & 6 & 6 & 11.96 & 99.44 & 0.384 \\
\cline { 2 - 6 } & 6 & 7.2 & 13.14 & 99.16 & 0.539 \\
\hline \multirow{3}{*}{ Method II } & 6 & 4.8 & 10.70 & 98.98 & 0.428 \\
\cline { 2 - 6 } & 6 & 6 & 11.98 & 99.66 & 0.224 \\
\cline { 2 - 6 } & 6 & 7.2 & 13.11 & 98.75 & 0.269 \\
\hline
\end{tabular}

Table 4: Precision

\begin{tabular}{|c|c|c|c|c|c|}
\hline \multicolumn{2}{|c|}{ Concentration $(\boldsymbol{\mu g} / \mathbf{m l})$} & \multicolumn{2}{|c|}{ Intraday Precision } & \multicolumn{2}{c|}{ Interday Precision } \\
\cline { 3 - 6 } \multicolumn{2}{|c|}{} & \% Amount Found & \%RSD (n=3) & \% Amount Found & \% RSD (n=3) \\
\hline \multirow{3}{*}{ Method I } & 6 & 100.2 & 0.70 & 100.3 & 0.43 \\
\cline { 2 - 6 } & 9 & 99.8 & 0.72 & 99.7 & 1.82 \\
\cline { 2 - 6 } & 12 & 99.7 & 0.20 & 100.6 & 1.10 \\
\hline \multirow{3}{*}{ Method II } & 6 & 100.3 & 0.31 & 100.1 & 0.61 \\
\cline { 2 - 6 } & 9 & 100.1 & 0.51 & 99.9 & 0.53 \\
\cline { 2 - 6 } & 12 & 99.8 & 0.11 & 100.1 & 1.24 \\
\hline
\end{tabular}

\section{Repeatability}

\begin{tabular}{|c|c|c|c|}
\hline & Concentration $(\boldsymbol{\mu g} / \mathbf{m l})$ & Amount found \% & \%RSD $(\mathbf{n}=\mathbf{6})$ \\
\hline Method I & 9 & 100.2 & 0.936 \\
\hline Method II & 9 & 99.9 & 0.862 \\
\hline
\end{tabular}

Table 5: Ruggedness

\begin{tabular}{|c|c|c|c|c|}
\hline & Analyst & Concentration $(\boldsymbol{\mu g} / \mathbf{m l})$ & Amount found \% & \%RSD $(\mathbf{n}=\mathbf{6})$ \\
\hline \multirow{2}{*}{ Method I } & I & 9 & 100.4 & 0.659 \\
\cline { 2 - 5 } & II & 9 & 99.7 & 0.960 \\
\hline \multirow{2}{*}{ Method II } & I & 9 & 100.1 & 0.636 \\
\cline { 2 - 5 } & II & 9 & 99.5 & 0.748 \\
\hline
\end{tabular}

$n=$ number of determinations

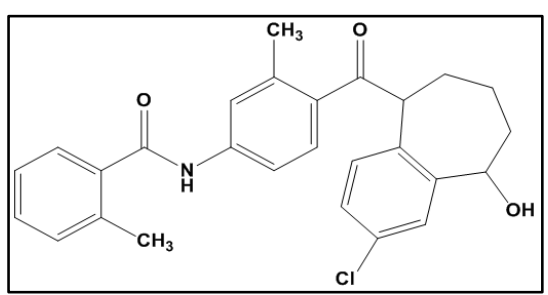

Fig. 1: The chemical structure of Tolvaptan
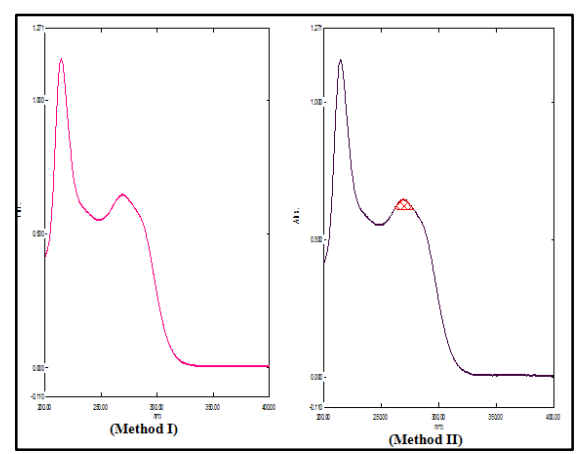

Figure 2: Method I. UV-spectrum of tolvaptan in SLS $(5 \% \mathrm{w} / \mathrm{v})$ showing $\lambda \max$; Method II.UVspectrum of tolvaptan in SLS (5\%w/v) showing selection of wavelength for integration of Zero order AUC

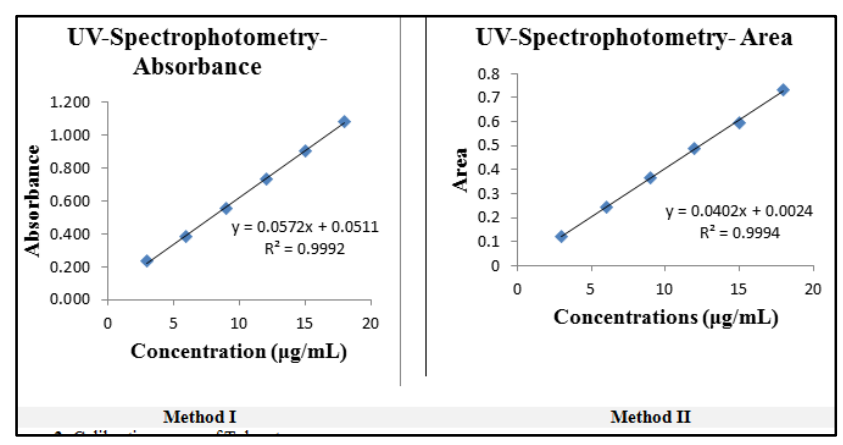

Fig. 3: Calibration curve of Tolvaptan.

\section{Conclusion}

The proposed methods for analysis of Tolvaptan in pharmaceutical formulations are ecofriendly, simple, precise and rapid so can be employed for routine analysis. From the proposed methods, we conclude that there is a good scope for other poorly water soluble drugs to get solubilized by using suitable hydrotropic agents. The developed methods have an advantage as organic solvents are avoided. 


\section{Acknowledgments}

Authors are thankful to Dr. S. J. Surana, Principal, R.C. Patel Institute of Pharmaceutical Educationfor providing necessary facilities for this work.

\section{Source of Funding}

None.

\section{Conflict of Funding}

None.

\section{References}

1. Hauptman PJ, Zimmer C, Udelson J, Shoaf SE, Mallikaarjun S, Bramer SL et al, Comparison of two doses and dosing regimens of tolvaptan in congestive heart failure. J Cardiovasc Pharm 2005;46(5):609-14.

2. Yi S, Jeon H, Yoon SH, Cho JY, Shin SG, Jang IJ et al, Pharmacokinetics and pharmacodynamics of oral tolvaptan administered in 15-to 60-mg single doses to healthy Korean men. J Cardiovasc Pharm 2012;59(4):315-22.

3. Anusha G, Kalaichelvi R. Analytical method development and validation of tolvaptan in its API and formulation by using PDA detector-RP-HPLC. Indo Am J Pharm Sci 2014;1(4):260-5.

4. Chakravarthy VK, Shankar DG. Development and validation of RP-HPLC method for estimation of Tolvaptan in bulk and its pharmaceutical formulation. Rasayan $J$ Chem 2011;4(1):165-71.

5. Murugan S, Kumar NP, Kumar CK, Sundhar VS, Harika S, Anusha $\mathrm{P}$ et al. Method development and validation for dissolution method of Tolvaptan in bulk and tablet dosage form by UV spectrophotometry. Indian J Pharm Sci Res 2013;3(1):17-9.

6. Sri KV, Sruthi S, Srinivas LD. UV Spectrophotometric Method for the Estimation of Tolvaptan in Bulk and Pharmaceutical Formulations. Asian J Res Chemistr 2014;7(9):2.

7. Choudhary AN, Nayal S. A review: Hydrotropy a solubility enhancing technique. Pharm Innov J 2019;8(4):1149-53.

8. Shukla RS, Patel A, Soni ML, Modi V, Jaliwala YA. Quantitative spectrophotometric estimation of cefadroxil using hydrotropic solubilization technique. Asian Journal of Pharmaceutics (AJP): Free full text articles from. Asian $J$ Pharm 2014;25;2(3).

9. Patil D. Spectroscopic determination of lovastatin by hydrotropic solubilization technique. Int J Pharm Chem Sci 2012;1:1142-4

10. Nwodo NJ, Nnadi CO, Nnadi KI. Development and validation of novel hydrotropic solubilization method for spectrophotometric determination of halofantrine in pure and solid dosage form. Scholar's Academic J Pharm 2013;2(4):298-303.

11. ICH Validation of analytical procedures: Text and methodology Q2 (R1), International Conference on Harmonization, 2005.

12. Indian Pharmacopoeia. Ministry of Health andFamily Welfare, Government of India, the IndianPharmacopoeial Commission, Ghaziabad,Vol. III, 2018;3403-4.

How to cite this article: Patil MR, Patil AS, Shirkhedkar AA. Novel and ecofriendly UVSpectrophotometry methods for estimation of tolvaptan using hydrotropic agent. Int $J$ Pharm Chem Anal 2019;6(4):115-9. 